This document is confidential and is proprietary to the American Chemical Society and its authors. Do not copy or disclose without written permission. If you have received this item in error, notify the sender and delete all copies.

\title{
Synergy of Two Assembly Languages in DNA Nanostructures: Self-Assembly of Sequence-Defined Polymers on DNA Cages
}

\begin{tabular}{|r|l|}
\hline Journal: & Journal of the American Chemical Society \\
\hline Manuscript ID & ja-2015-12953d.R1 \\
\hline Manuscript Type: & Article \\
\hline Date Submitted by the Author: & 08-Mar-2016 \\
\hline Complete List of Authors: & $\begin{array}{l}\text { Chidchob, Pongphak; McGill University, Chemistry } \\
\text { Edwardson, Thomas; McGill University, Chemistry } \\
\text { Serpell, Christopher; McGill University, Department of Chemistry } \\
\text { Sleiman, Hanadi; McGill University, Department of Chemistry }\end{array}$ \\
\hline
\end{tabular}

SCHOLARONE ${ }^{m}$

Manuscripts 


\title{
Synergy of Two Assembly Languages in DNA Nanostructures: Self-Assembly of Sequence-Defined Polymers on DNA Cages
}

Pongphak Chidchob, Thomas G. W. Edwardson, Christopher J. Serpell, \& Hanadi F. Sleiman*

Department of Chemistry and Centre for Self-Assembled Chemical Structures (CSACS-CRMAA), McGill University, 801 Sherbrooke Street West, Montreal, Quebec H3A 0B8, Canada

\begin{abstract}
DNA base-pairing is the central interaction in DNA assembly. However, this simple four-letter (A-T and G-C) language makes it difficult to create complex structures without using a large number of DNA strands of different sequences. Inspired by protein folding, we introduce hydrophobic interactions to expand the assembly language of DNA nanotechnology. To achieve this, DNA cages of different geometries are combined with sequence-defined polymers containing long alkyl and oligoethylene glycol repeat units. Anisotropic decoration of hydrophobic polymers on one face of the cage leads to hydrophobically-driven formation of quantized aggregates of DNA cages, where polymer length determines the cage aggregation number. Hydrophobic chains decorated on both faces of the cage can undergo an intra-scaffold 'handshake' to generate DNA-micelle cages, which have increased structural stability and assembly cooperativity, and can encapsulate small molecules. The polymer sequence order can control the interaction between hydrophobic blocks, leading to unprecedented 'doughnut-shaped' DNA cage-ring structures. We thus demonstrate that new structural and functional modes in DNA nanostructures can emerge from the synergy of two interactions, providing an attractive approach to develop protein-inspired assembly modules in DNA nanotechnology.
\end{abstract}




\section{Introduction}

Sequence-controlled polymers, such as oligonucleotides and polypeptides, are remarkable macromolecules in which the order of the building blocks along the polymer chain provides all necessary instructions for efficient structural control, molecular recognition and catalysis. ${ }^{1}$ In particular, polypeptide chains are programmed to fold themselves into final predetermined structures with very high accuracy to construct important biological nanomachines. Although such a level of structural and functional complexity has not been fully realized synthetically, ${ }^{1}$ the field of DNA nanotechnology offers a powerful tool to create finely designed two- and three-dimensional architectures and devices by using DNA as the main building block. ${ }^{2-11}$ However, a large number of DNA strands of unique sequences are generally required for the assembly of more complex structures. This decreases scalability and can theoretically increase assembly errors, due to the limited four-letter A-T and G-C 'language' in DNA assembly.

The incorporation of multiple molecular interactions within the same building block is an efficient strategy to achieve complex and hierarchical assembly in biological systems. Of these, hydrophobic interactions are the underlying mechanism for many structural elements in biology such as phospholipid bilayers, vesicles and many proteins. They are also a fundamental driving force for the selfassembly of synthetic block copolymers into various morphologies such as spherical micelles, cylindrical micelles and vesicles. ${ }^{12}$ The integration of hydrophobic interactions with DNA base-pairing is a promising approach not only to overcome the complexity-scalability-error issues, but also to introduce new assembly modes and functionalities in DNA assembly. ${ }^{13,14}$ Inspired by protein folding, we would like to create assembly modules, like protein coiled-coil motifs, as elementary repeats in DNA nanotechnology, thus we need to understand the rules governing the interplay between the two languages in the assembly. However, one of the problems is the difficulty in the synthesis of DNA conjugated with hydrophobic molecules and polymers. Our group has recently developed an automated solid-phase synthesis to prepare monodisperse DNA-polymer conjugates based on phosphoramidite chemistry. ${ }^{15}$ This approach is not only convenient, rapid and high yielding but also allows one to place functional monomers in a sequence-controlled manner on the polymer backbone.

The combination of DNA base-pairing with hydrophobic interactions can expand assembly modes to DNA nanostructures which would not be possible otherwise. DNA cages have emerged as promising platform for cellular delivery of therapeutics. ${ }^{16-20}$ However, unmodified DNA/RNA structures suffer from nuclease instability, poor cellular penetration and rapid clearance in vivo. ${ }^{16-20}$ Attaching hydrophobic functionalities and increasing the assembly range of DNA cages can be an effective method to overcome these barriers. To our knowledge, the implementation of hydrophobic interactions in the 
design of DNA nanostructures is still considerably unexplored. Some examples that integrate hydrophobic interactions with DNA nanostructures include self-folding of DNA rectangles mediated by cholesterol $^{21}$ and hydrophobic dendritic molecules, ${ }^{22}$ and DNA tetrahedra functionalized with a thermoresponsive polymer that can transition between a discrete tetrahedron and giant-surfactant aggregates. ${ }^{23}$ Recent work by our group has demonstrated the significant role of hydrophobic interactions in directing the association of alkyl chains on three-dimensional DNA scaffolds. The number and position of the chains on DNA cubes can dramatically alter their assembly behavior. ${ }^{14,24}$

In this article, we report an in-depth study of the self-assembly of sequence-defined hydrophobic polymers on DNA cages (Figure 1). Our system allows the systematic change of cage structure and size, and orientation of individual polymer chains on the DNA scaffold. On the polymer end, the polymers are monodisperse and sequence controlled in such a way that we can precisely change the number of hydrophobic repeats, the relative number of hydrophilic to hydrophobic repeats, and the polymer sequence. We found that decoration of the polymers on the cages leads to new DNA super-structures through hierarchical assembly, via DNA base-pairing and hydrophobic interactions. (i) Short hydrophobic chains result in monomeric DNA cage structures. (ii) Intermediate chains arranged on one face of the DNA cage result in quantized cage assemblies, where a specific number of DNA cages is organized around a hydrophobic core; here, the number of repeats in the polymer defines the size of the hydrophobic core, and dictates number of DNA cages that form these aggregates. (iii) Hydrophobic chains on both faces of the cage undergo an intra-scaffold 'handshake', to give DNA-micelle cages. Hydrophobic interactions not only mediate the encapsulation of small molecules in the cage, but also significantly increase structural stability and assembly cooperativity. (iv) Specific polymer sequences result in unprecedented doughnut-shaped DNA cage-ring structures, where DNA cages are organized into rings, whose diameter and density can be controlled by varying the length of the polymer blocks. We propose a mechanism for the hydrophobically-driven quantized self-assembly that is dependent on the chain length of the polymers, and we study the dynamic ability of the quantized DNA cage assemblies to undergo structural exchange. We thus demonstrate the efficient use of sequence-defined hydrophobic polymers to create orthogonal assembly modes which synergistically combine hydrophobic and base pairing interactions in the assembly of DNA nanostructures. 

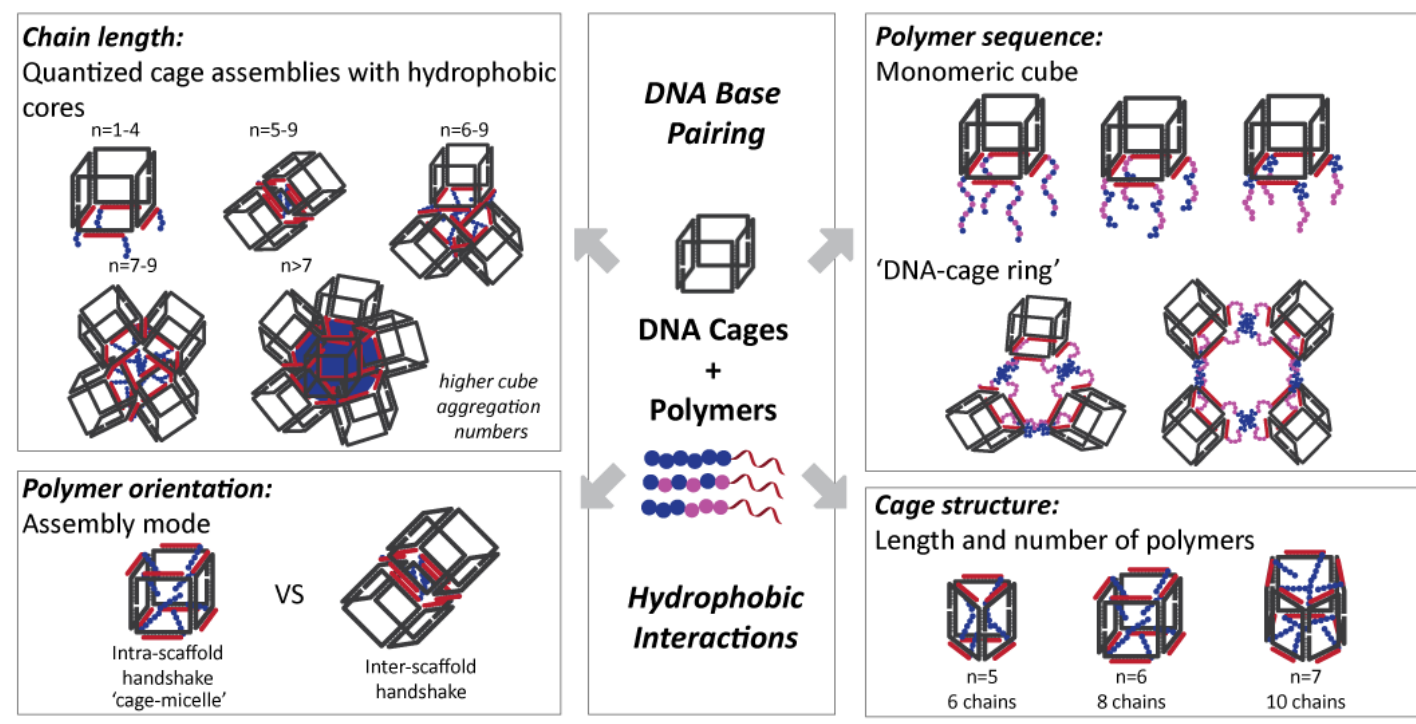

Hydrophobic cage-micelle' handshake

Figure 1. Schematic representation of the self-assembly of sequence-defined hydrophobic polymers on DNA cages. The blue and magenta circles denote hydrophobic and hydrophilic monomers along the polymer chains, where ' $n$ ' is the number of hydrophobic repeats. Top Left, Hydrophobic polymers on one face of DNA cage lead to 'quantized cage assemblies', whose aggregation number depends on the number of hydrophobic polymer repeats. Top right, Depending on their sequence, polymers with hydrophilic and hydrophobic repeats give monomeric cages, or donut-shaped 'cage-rings'. Bottom left, when both faces of the DNA cage have hydrophobic polymers, they can undergo an intra-scaffold 'handshake' into a 'cagemicelle' that encapsulates small molecules and is significantly more stable than the unsubstituted cage. Bottom right, depending on cage geometry, the intra-scaffold 'handshake' occurs with a different number of hydrophobic polymer repeats, with different capacity for small molecules.

\section{Results and discussion}

\section{Design of DNA cages and sequence-defined DNA-polymer conjugates}

DNA cages were chosen as scaffolds for three-dimensional positioning of DNA-polymer conjugates and were assembled via a 'clip-by-clip' approach. ${ }^{14,24}$ The clips are 80-mer DNA strands composed of four single-stranded segments separated by a hexaethyloxy-glycol (HEG) spacer. The 20mer segment in the middle of the clip can hybridize to two peripheral 10-mer segments of the next clip. Cube (C) can be constructed from four clips where the fourth clip folds back and hybridizes to the first clip, cyclizing the cubic assembly (Figure 2a). This structure presents 820 -mer segments that are singlestranded, and provide binding sites for DNA-polymer conjugates. In a similar approach, triangular prism 
(TP) and pentagonal prism (PP) can be generated from three and five clips, respectively, and structures were generated in quantitative or near quantitative yields (see Section V in Supporting Information).

To prepare sequence-defined DNA-polymer conjugates, 1,12-dodecane-diol (hexaethylene, HE) and hexaethyloxy-glycol (HEG) were chosen as hydrophobic and hydrophilic monomers (Figure $2 \mathrm{~b}$ ). These monomers were attached to a 19-mer DNA by automated solid-phase synthesis using phosphoramidite chemistry. ${ }^{15}$ The DNA segments contain a $5 \mathrm{~T}$ spacer and 14-mer complementary sequence to the single-stranded segments on the cages. A series of DNA-HE conjugates and DNAHE/HEG copolymer conjugates were synthesized to systematically investigate the design parameters of DNA-polymer conjugates for their assembly behavior on DNA cages (Figure 1b, and see Section IV in Supporting Information).

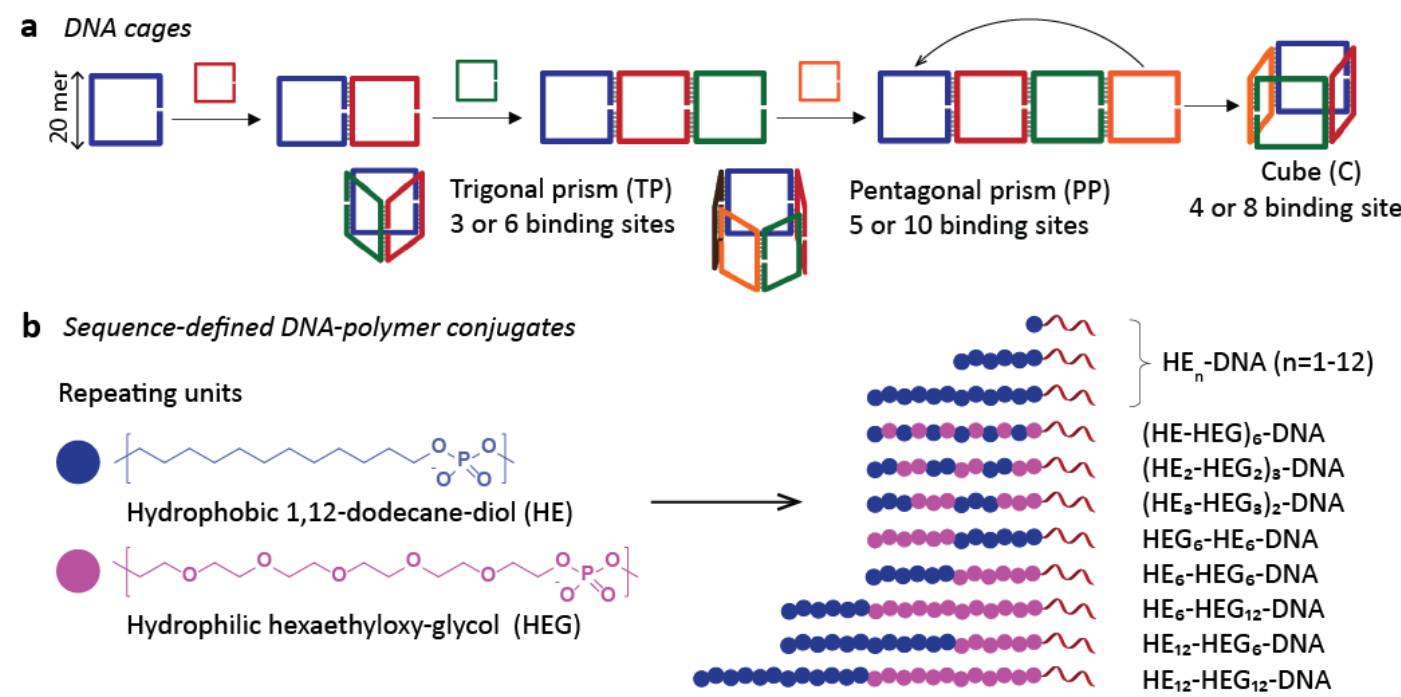

Figure 2. Cage and DNA-polymer conjugate design. a) Clip-by-clip approach for DNA cage construction. A cube can be constructed from four different 80-mer DNA clips and contains maximum of 8 binding sites. b) Hydrophilic hexaethyloxy-glycol (HEG) and hydrophobic 1,12-dodecane-diol (HE) monomers for the synthesis of sequence-defined DNA-polymer conjugates. The 14-mer single-stranded DNA can hybridize to the single-stranded segments on the cages.

\section{Polymers: number of hydrophobic repeats}

We had previously decorated DNA cubes with dendritic alkyl chains, and showed that a cube with 4 dendritic units on one of its faces can associate into a dimer via an intermolecular 'handshake' of the hydrophobic units. ${ }^{14}$ We also introduced hydrophobic polymers $\mathrm{HE}_{\mathrm{n}}$-DNA (Figure $2 \mathrm{~b}$ ) on one face of a DNA cube, and preliminarily showed their assembly into discrete aggregates, which we hypothesized to be cube dimer, tetramer, hexamer, etc. ${ }^{24}$ With a very long alkyl component in $\operatorname{HE}_{n}-\mathrm{DNA}(\mathrm{n}=12)$ on one 
face of a DNA cube, we showed the formation of a spherical micelle with a hydrophobic core, and DNA cubes on its exterior. This cube micelle displayed dynamic character (cubes can be removed by strand displacement), the ability to form higher-order micelle networks, and to act as a scaffold to organize fluorescent dyes into an antenna structure with controlled FRET. ${ }^{24}$

To develop a better understanding of the rules for this hydrophobically driven assembly, it was crucial to further characterize the molecularity of the quantized cage aggregates. We thus examined the effect of the chain length of hydrophobic polymers $\mathrm{HE}_{\mathrm{n}}$-DNA on their assembly with DNA cages (Figure 3a, we name the DNA sequence on the polymer 'DNA'). Cube $\mathrm{C}_{4}$ has four identical single-stranded stretches on one of its faces, each complementary to the DNA strand of the DNA-polymer conjugates. The decoration $\mathrm{C}_{4}$ with four $\mathrm{HE}_{\mathrm{n}}$-DNA was achieved by mixing all components in magnesium-containing buffer then thermally annealing from $95^{\circ} \mathrm{C}$ to $4^{\circ} \mathrm{C}$ over 4 hours. The formation of DNA nanostructures was followed by native polyacrylamide gel electrophoresis (PAGE) as shown in Figure 3b. Addition of four complementary unmodified DNA strands to $\mathrm{C}_{4}$ yielded a single band of lower electrophoretic mobility. Addition of strands with short hydrophobic chains to one face of cube $\mathrm{C}_{4}$, from $\mathrm{HE}_{1}$-DNA to $\mathrm{HE}_{4}$-DNA, resulted in single bands of similar electrophoretic mobility compared to $\mathrm{C}_{4}$ with unmodified DNA, consistent with a monomeric cube. The lack of difference in electrophoretic mobility for these cubes as the number of hydrophobic repeats in $\mathrm{HE}_{\mathrm{n}}$-DNA increases $(\mathrm{n}=1-4)$ is possibly consistent with some chain folding or interaction of these chains across one face of the cube in a manner that does not impede the movement of the assemblies on native PAGE. Thus, when DNA-polymer conjugates with 1-4 hydrophobic repeats were added to one face of the cube, monomeric structures decorated with hydrophobic groups are formed.

When longer hydrophobic chains from $\mathrm{HE}_{5}$-DNA to $\mathrm{HE}_{12}$-DNA were added to $\mathrm{C}_{4}$, we no longer see the monomeric cube as a major product. Instead, we observe the combination of cubes into discrete aggregates. This is likely due to the increased hydrophobicity of the polymer chains attached to the cube, promoting cube association to hide these hydrophobic chains in the core (akin to a protein coiled-coil motif). The identity of $\mathrm{C}_{4} / \mathrm{HE}_{6}$-DNA was elucidated by atomic force microscopy (AFM). Figure $3 \mathrm{c}$ reveals elongated structures of two spheres, which accounted for $76 \%$ of population (cube dimers), and triangular structures with the edge length of $\sim 30 \mathrm{~nm}$ (cube trimers, see below). Some disaggregation of the higher-order structures into individual cubes (diameter of $\sim 17-18 \mathrm{~nm}$ ) was also noted on the mica surface, and can be attributed to strong electrostatic interactions between DNA and mica, that compete with the hydrophobic interactions holding together the DNA nanostructures. ${ }^{21}$ The hydrodynamic size measured by dynamic light scattering (DLS) indicates that $\mathrm{C}_{4} / \mathrm{HE}_{6}-\mathrm{DNA}$ had low polydispersity, but was 
not able to differentiate between the two populations of higher-order structures (Figure $3 \mathrm{~d}$, and see Section XIX in Supporting Information for isolation of the individual higher-order structures).

To further support the identity of $\mathrm{C}_{4} / \mathrm{HE}_{6}$-DNA, we tagged each cube with a gold nanoparticle (see Section VIII in Supporting Information) and preliminarily characterized the assemblies by transmission electron microscopy (TEM). We observed a larger population of the clusters containing 2 and 3 AuNPs in close proximity (see Supplementary Figure 15). The technique was complicated by sample-surface interactions, which sometimes resulted in populations of higher-order aggregates. However, these observations are consistent with dimeric and trimeric structures as the identity of the higher-order structures for $\mathrm{C}_{4} / \mathrm{HE}_{6}$-DNA. 


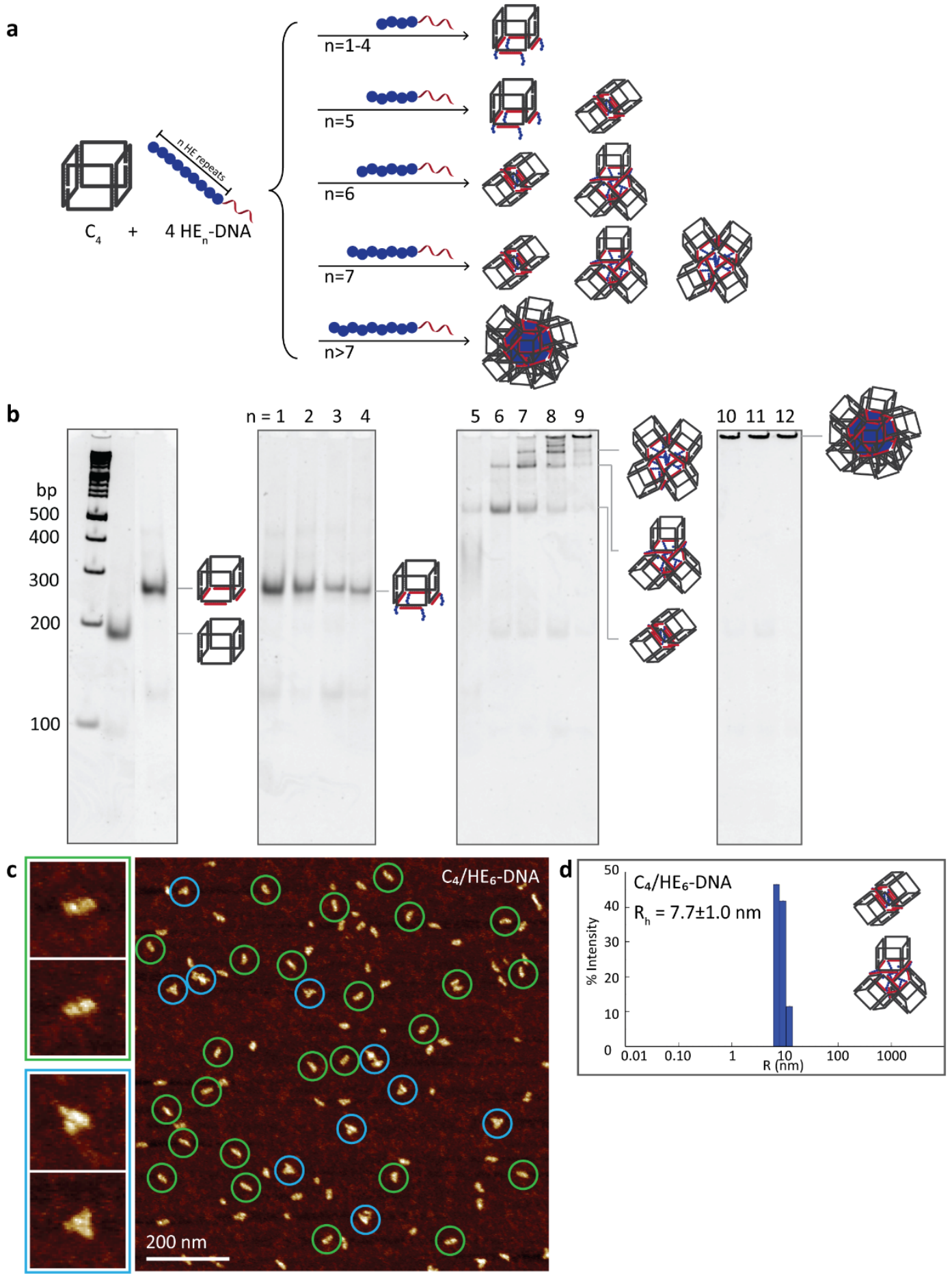

Figure 3. Decoration of one face of $\mathrm{C}_{4}$ with four $\mathrm{HE}_{\mathrm{n}}$-DNA (n=1-12). a) Assembly products of $\mathrm{C}_{4}$ with $\mathrm{HE}_{\mathrm{n}}$-DNA. Finite cube aggregation number that scales with the number of hydrophobic polymer repeats are observed. b) Native PAGE showing the assembly of $\mathrm{C}_{4}, \mathrm{C}_{4} / \mathrm{DNA}$ and $\mathrm{C}_{4} / \mathrm{HE}_{\mathrm{n}}$-DNA. c) AFM image of $\mathrm{C}_{4} / \mathrm{HE}_{6}$-DNA showing cube dimers (green circles) and cube trimers (blue circles). d) Size distribution 
histogram of $\mathrm{C}_{4} / \mathrm{HE}_{6}$-DNA obtained from DLS. (see Supplementary Figure 26 for additional AFM images)

As the number of hydrophobic HE repeats on the polymer increased, increasingly large superstructures were formed. Interestingly, their aggregation number correlated with the number of HE repeats. Comparison of these bands to the DNA ladder allowed an estimation of relative 'molecular weight' for each higher-order structure, and we can calculate a cube aggregation number by comparing these molecular weights to that of the monomeric structure. The results suggest that the cube aggregation number gradually increases by increments of one (see Section VII in Supporting Information). Thus, $\mathrm{HE}_{7^{-}}$ DNA gives dimer, trimer and tetramer, and $\mathrm{HE}_{8}$-DNA gives trimer, tetramer and pentamer. $\mathrm{HE}_{9}$-DNA to $\mathrm{HE}_{12}$-DNA give non-penetrating bands, which may be composed of incrementally higher cube aggregation numbers. However, it should be noted that the relationship between cube aggregation number and electrophoretic mobility can also be nonlinear.

\section{Polymers: sequences of the polymers and relative numbers of hydrophilic to hydrophobic repeats}

The monomer sequence along polymer chains can significantly influence polymer physical properties. To investigate this effect on DNA cages, we assembled cube $\mathrm{C}_{4}$ with a series of copolymers of different sequences, all containing a constant number of 6 hydrophobic HE and 6 hydrophilic HEG repeats per chain. This includes alternating chains of single monomers (HE-HEG) ${ }_{6}$-DNA, two monomers $\left(\mathrm{HE}_{2}-\mathrm{HEG}_{2}\right)_{3}$-DNA, three monomers $\left(\mathrm{HE}_{3}-\mathrm{HEG}_{3}\right)_{2}$-DNA and six monomers (Figure 4a). The latter polymer has two sequences; $\mathrm{HEG}_{6}-\mathrm{HE}_{6}$-DNA, in which the hydrophobic portion is between the DNA and HEG chains, and $\mathrm{HE}_{6}-\mathrm{HEG}_{6}$-DNA, in which the hydrophobic portion is at the chain-end. Only the latter structure among this copolymer series was previously shown to assemble into micellar aggregates, whereas the other structures remain as unimers in solution. ${ }^{15}$

Decoration of these HE/HEG-DNA polymers on cube $\mathrm{C}_{4}$ yielded monomeric structures (Figure $4 \mathrm{~b}$, with one exception, see below). The electrophoretic mobility of these structures on native PAGE increased with HE block length, consistent with greater structure compaction. As the HE block becomes longer, the local hydrophobicity of individual HE segments increases, thus potentially enabling more efficient folding of the hydrophobic chains, which can make the structures increasingly compact and increases their gel mobility. Interestingly, these polymers did not result in cube aggregation, despite their relatively high hydrophobic content. These cages are especially interesting for applications in cellular delivery: they behave as monomers, yet their hydrophobic content can facilitate interaction with cellular membranes and modify their delivery profile. ${ }^{18,19,25,26}$ It is of note that this behavior is a direct result of 
sequence control of the polymers, where regular block copolymers would not be able to generate this property.

The exception to this monomeric assembly was $\mathrm{C}_{4} / \mathrm{HE}_{6}-\mathrm{HEG}_{6}-\mathrm{DNA}$, which gave higher-order structures that appeared as a non-penetrating band on the native PAGE. The AFM images (Figure 4c) reveal polygonal rings containing 3-5 vertices with edge length of $\sim 30 \mathrm{~nm}$. The size of the structures was also supported by DLS measurements $\left(\mathrm{R}_{\mathrm{h}}=14 \mathrm{~nm}\right)$. We believe that the flexible HEG block is able to serve as a spacer between hydrophobic HE domains and the cubes. The HE block of $\mathrm{HE}_{6}-\mathrm{HEG}_{6}-\mathrm{DNA}_{\mathrm{N}}$ can form hydrophobic domains by interacting with the chains on the other cubes side-to-side, resulting in polygonal rings. As the HEG block might be a crucial parameter for the diameter of the ring-like structures, we hypothesized that a longer HEG block could create structures with larger spacing between the cubes. The hydrodynamic radius of $\mathrm{C}_{4} / \mathrm{HE}_{6}-\mathrm{HEG}_{12}$-DNA $(18 \mathrm{~nm})$ was indeed significantly larger than that of $\mathrm{C}_{4} / \mathrm{HE}_{6}-\mathrm{HEG}_{6}$-DNA. However, in this case, we also observed disassembly of some of the structures on the mica surface by AFM, which is likely due to the larger hydrophilic-to-hydrophobic content of this polymer (Figure 4c).

To further increase the stability of this hydrophobic inter-scaffold 'handhake', we assembled $\mathrm{C}_{4} / \mathrm{HE}_{12}-\mathrm{HEG}_{6}$-DNA, which has a longer hydrophobic HE block than $\mathrm{C}_{4} / \mathrm{HE}_{6}-\mathrm{HEG}_{6}-\mathrm{DNA}$. This molecule generated a high yield of well-defined ring-like structures with hollow features in the middle as observed by AFM (Figure $4 \mathrm{c}$ ). Further increasing the length of the HEG block to $\mathrm{C}_{4} / \mathrm{HE}_{12}-\mathrm{HEG}_{12}-\mathrm{DNA}$ also showed efficient formation of ring structures, which looked denser by AFM. The radii of both structures were comparable $\left(20 \mathrm{~nm} / 27 \mathrm{~nm}\right.$ (DLS/AFM) for $\mathrm{C}_{4} / \mathrm{HE}_{12}-\mathrm{HEG}_{6}-\mathrm{DNA} ; 21 / 24 \mathrm{~nm}$ (DLS/AFM) for $\mathrm{C}_{4} / \mathrm{HE}_{12}-\mathrm{HEG}_{12}$-DNA, Figure $4 \mathrm{c}$ and see Section XI in Supporting Information for DLS). TEM characterization also confirmed the presence of relatively homogeneous spherical structures (radius $12 \mathrm{~nm}$ for $\mathrm{C}_{4} / \mathrm{HE}_{12}-\mathrm{HEG}_{6}-\mathrm{DNA}$ and $15 \mathrm{~nm}$ for $\mathrm{C}_{4} / \mathrm{HE}_{12}-\mathrm{HEG}_{12}-\mathrm{DNA}$, see Section XIII in Supporting Information). It should be noted that the sizes obtained from AFM and DLS were similar to one another, and were significantly larger than those obtained by TEM, suggesting that the structures may be ring-like in solution. The possible explanation for the smaller sizes measured by TEM is a collapse of the structures on the hydrophobic carbon-coated grids and the drying of DNA structures under high vacuum. $^{27}$

The estimated yields of the doughnut-shaped structures obtained by examination of the AFM images were high in all cases, except for the sequence in which the HE block is short (6 units) as compared to the HEG block (12 units). It was difficult to provide a precise yield from the AFM images, because of the presence of some misassembled structures of unknown composition in the image 
background. Thus, we can conclude that the addition of HEG repeats provides a spacer between DNA scaffolds and yields ring structures. To our knowledge, the assembly of DNA cages into 'doughnut-like' ring structures is unprecedented. It is interesting that, despite the flexibility of both HE and HEG chains, we observed discrete cube assemblies here, rather than linear oligomers. 
a

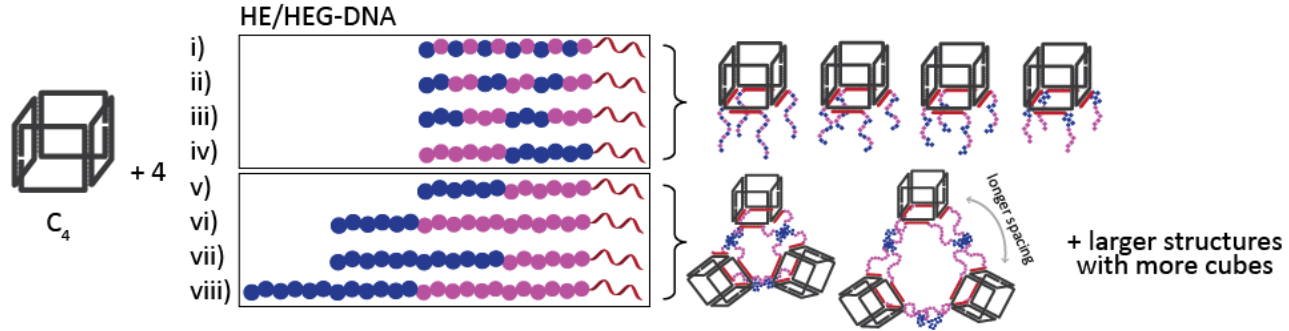

b

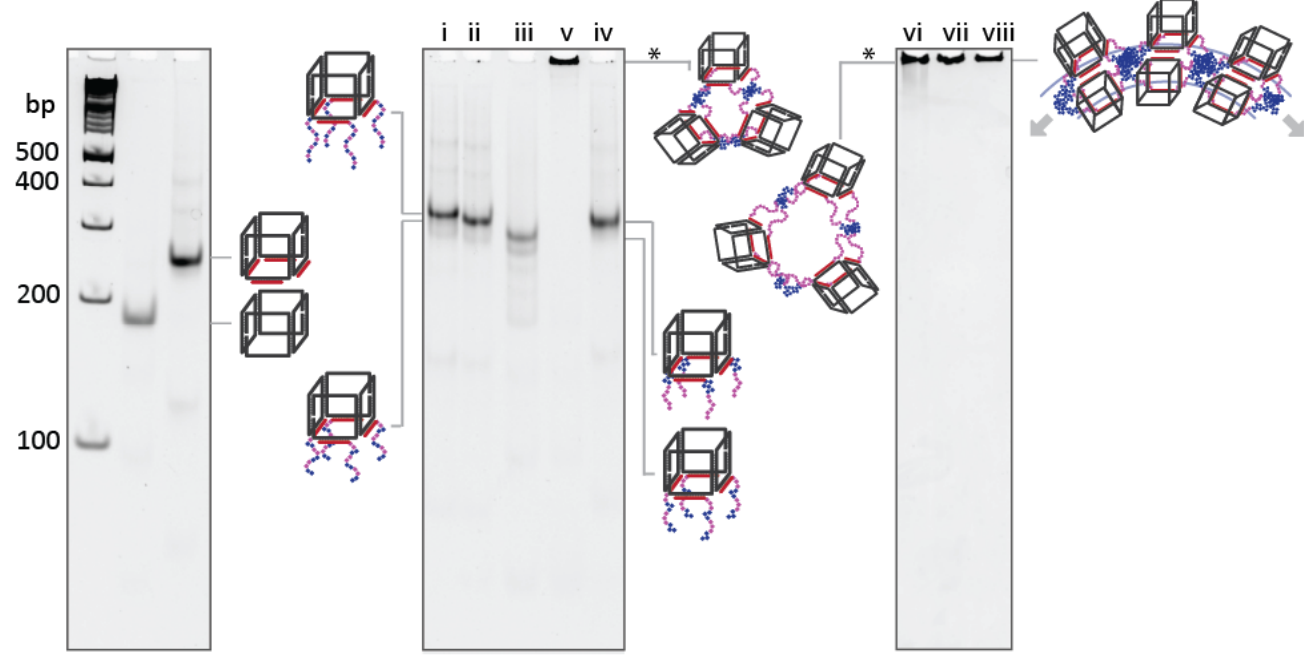

C
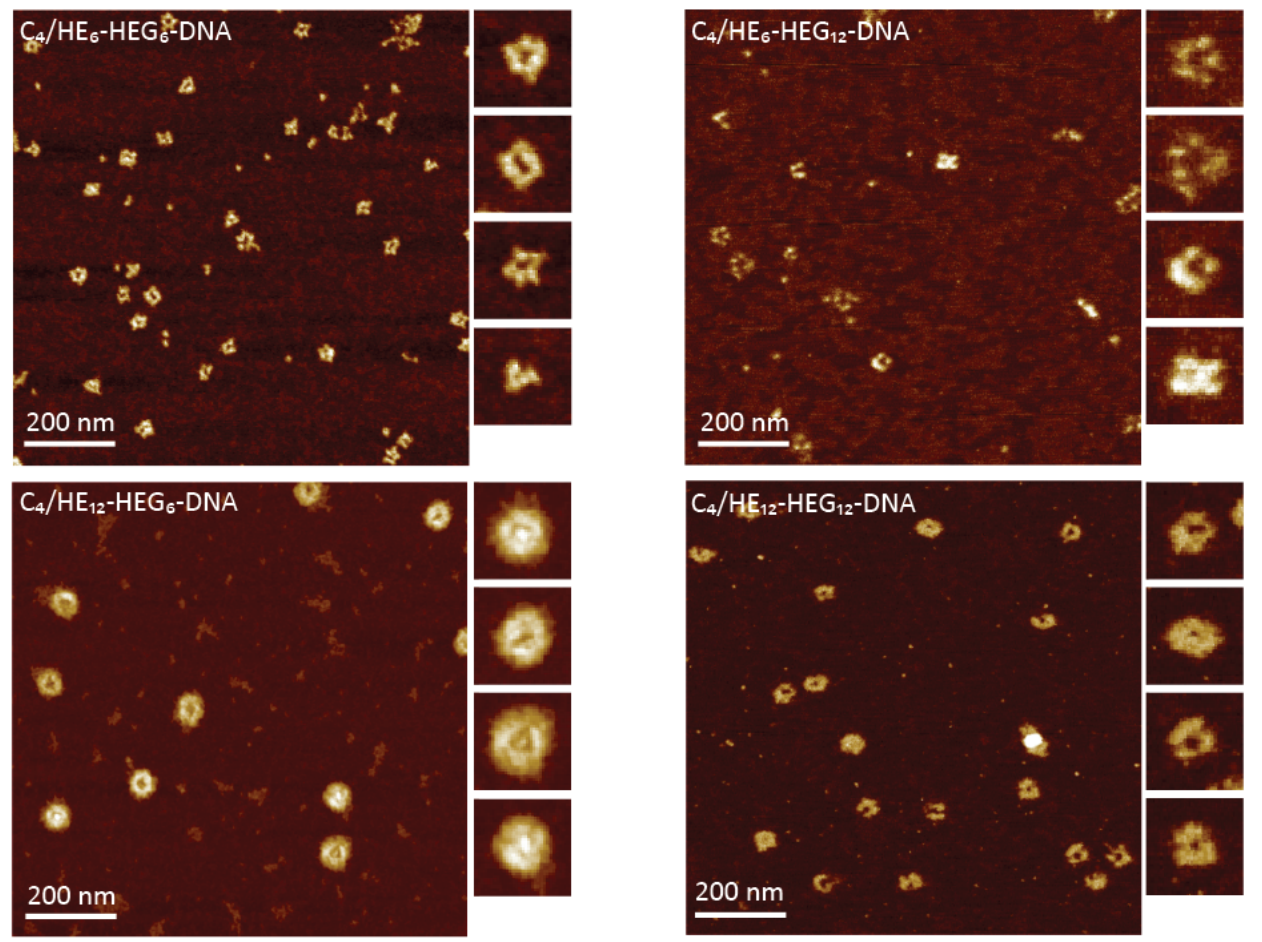

Figure 4. Decoration of $\mathrm{C}_{4}$ with four HE/HEG-DNA. a) Assembly products of $\mathrm{C}_{4}$ with HE/HEG-DNA. The polymer sequences can dictate whether the assembly either yields a monomeric cube or forms higherorder structure. b) Native PAGE showing the assembly of $\mathrm{C}_{4}, \mathrm{C}_{4} / \mathrm{DNA}, \mathrm{C}_{4}$ with HE/HEG-DNA. * Only 
the schematics of 3-vertices rings were shown here for $\mathrm{C}_{4} / \mathrm{HE}_{6}-\mathrm{HEG}_{6}-\mathrm{DNA}$ and $\mathrm{C}_{4} / \mathrm{HE}_{6}-\mathrm{HEG}_{12}-\mathrm{DNA}$. c) AFM images of $\mathrm{C}_{4}$ with $\mathrm{HE}_{\mathrm{n}}-\mathrm{HEG}_{\mathrm{m}}$-DNA $(\mathrm{n}=6,12$ and $\mathrm{m}=6,12)$. The presence of HEG block in the polymer chains can increase the spacing between the cubes.

\section{Cages: orientation of the polymer chains on the cages}

We previously reported that 8 dendritic HE units attached on both faces of a DNA cube result in an intramolecular association, with the ability to encapsulate molecules in the internal hydrophobic environment. ${ }^{14}$ We were interested in probing the dependence of this phenomenon on polymer architecture and chain length (e.g., how many how many hydrophobic chains can fit inside the cage?). Cube $\mathrm{C}_{8}$ was designed to allow decoration with up to 8 polymer chains on both its top and bottom faces (Figure 5a). A one-pot assembly of $\mathrm{C}_{8}$ with $\mathrm{HE}_{\mathrm{n}}$-DNA was performed. In Figure $5 \mathrm{~b}$, short HE chains generated monomeric structures with a sharp band on the gel. Interestingly, as the number of hydrophobic repeats increased, the electrophoretic mobility of this band increased (rather than decreased); it then remained constant at $\mathrm{HE}_{4}$-DNA until $\mathrm{HE}_{6}$-DNA. The structure of $\mathrm{C}_{8} / \mathrm{HE}_{6}$-DNA was characterized by AFM, which revealed mostly single spherical features with a radius of $9.6 \pm 4.8 \mathrm{~nm}$, comparable to $\mathrm{C}_{8}$ (see Supplementary Figures 32 and 33). DLS measurements (Figure 5c) indicated that $\mathrm{C}_{8} / \mathrm{HE}_{6}-\mathrm{DNA}$ $\left(\mathrm{R}_{\mathrm{h}}=6.4 \pm 0.3 \mathrm{~nm}\right)$ was smaller than $\mathrm{C}_{8} / \mathrm{DNA}\left(\mathrm{R}_{\mathrm{h}}=7.1 \pm 0.6 \mathrm{~nm}\right)$. A likely assembly mode here is that HE chains $\left(\mathrm{HE}_{4}-\mathrm{HE}_{6}\right)$ collapse and create a hydrophobic core inside the cube, resulting in a more compact structure similar to that of dendritic HE chains. ${ }^{14}$ The formation of the hydrophobic core in $\mathrm{C}_{8} / \mathrm{HE}_{6}-\mathrm{DNA}$ was further supported by the encapsulation of hydrophobic Nile Red fluorescent dye. ${ }^{28}$ Compared to a cube decorated with unmodified DNA, there was a significantly higher fluorescent signal of Nile Red in $\mathrm{C}_{8} / \mathrm{HE}_{6}$-DNA (Figure 5d).

As the number of hydrophobic repeats on the polymer increased, $\mathrm{HE}_{7}-\mathrm{DNA}$ started to form a cube dimer and longer hydrophobic chains resulted in higher-order structures as the major product. Thus, up to $6 \mathrm{HE}$ chains per polymer can be accomodated in the cube core (a total of $48 \mathrm{HE}$ chains), beyond which intermolecular assembly sets in. Both AFM and DLS measurements suggested that extended structures formed in the case of $\mathrm{C}_{8} / \mathrm{HE}_{8}$-DNA and $\mathrm{C}_{8} / \mathrm{HE}_{12}$-DNA (see Section XI and XII in Supporting Information for DLS and AFM). 
a

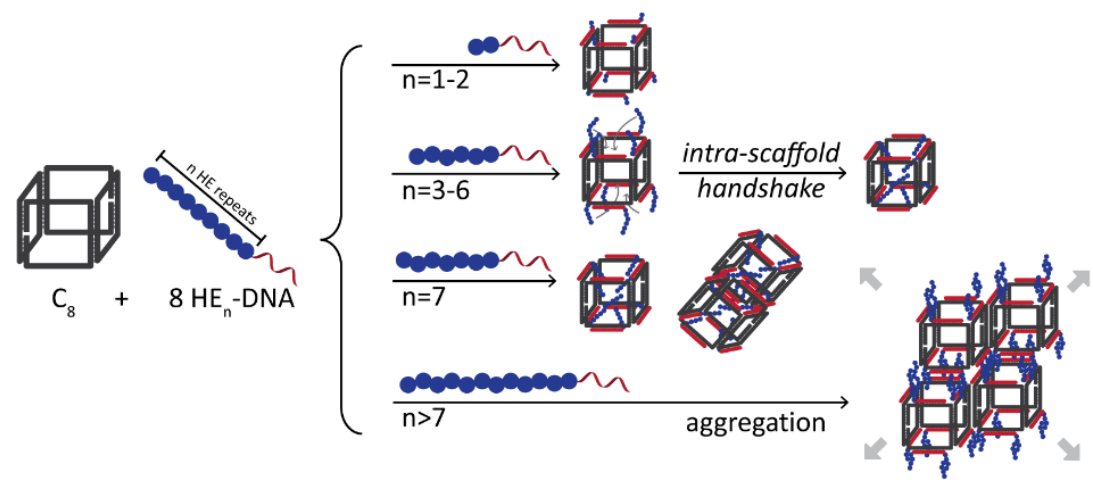

b
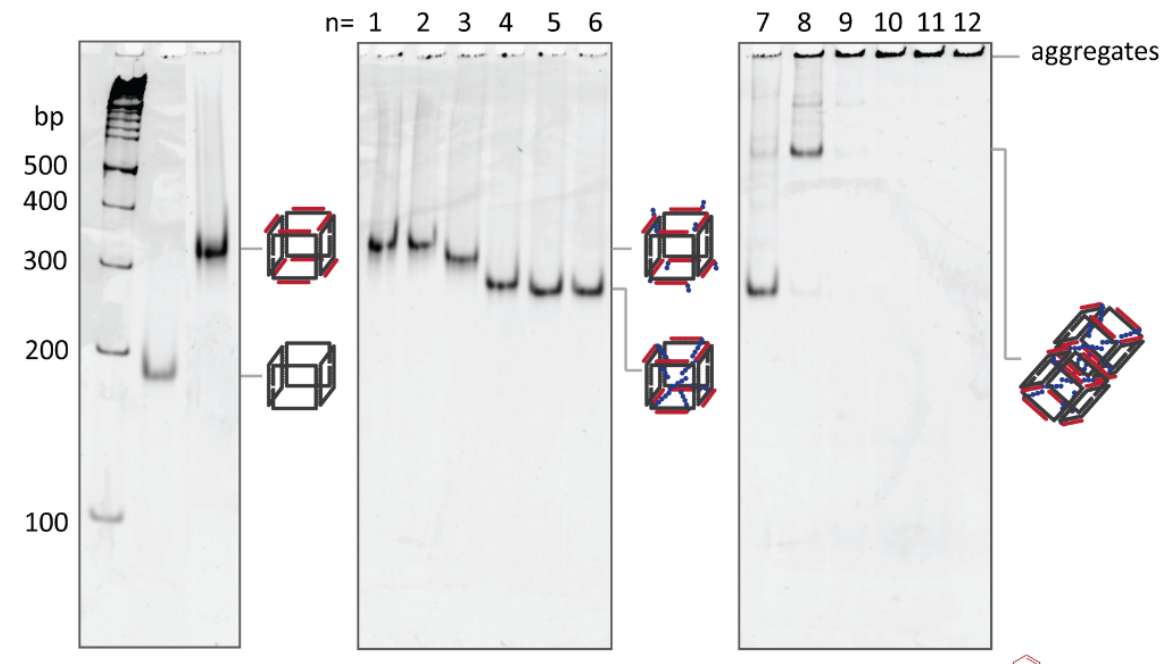

C
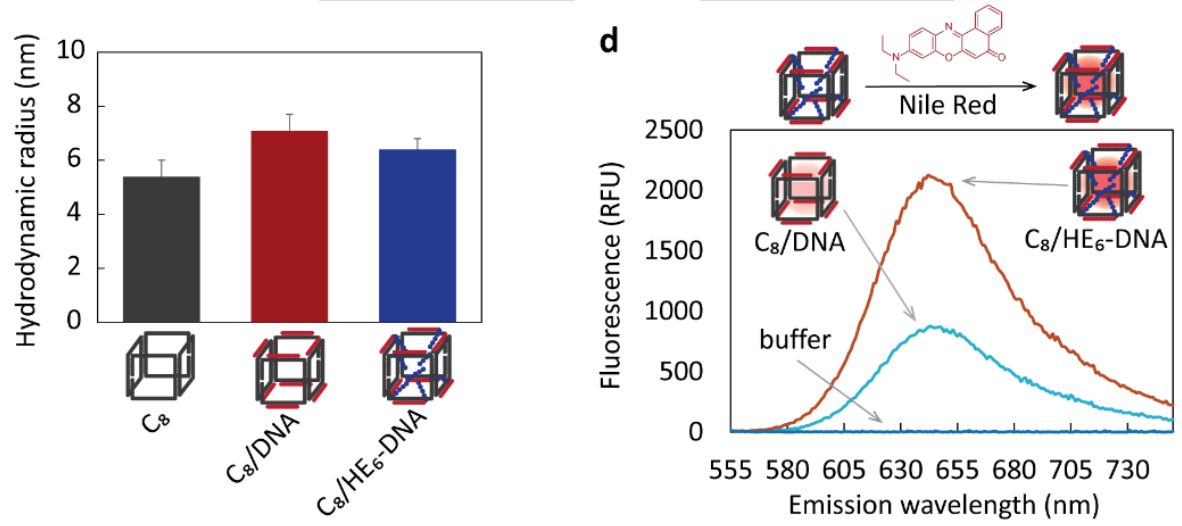

Figure 5. $\mathrm{C}_{8}$ assembly with $\mathrm{HE}_{\mathrm{n}}$-DNA $(\mathrm{n}=1,12)$ on its two faces. a) Assembly products of $\mathrm{C}_{8}$ with $\mathrm{HE}_{\mathrm{n}}$ DNA. Medium chain length of hydrophobic polymers $(n=3-6)$ prefers 'intra-scaffold handshake' and create hydrophobic core inside the cube. b) Native PAGE showing the assembly products of $\mathrm{C}_{8}, \mathrm{C}_{8} / \mathrm{DNA}$ and $\mathrm{C}_{8} / \mathrm{HE}_{\mathrm{n}}$-DNA. c) Hydrodynamic radii of $\mathrm{C}_{8}, \mathrm{C}_{8} / \mathrm{AT}$ (7.1 $\left.\pm 0.6 \mathrm{~nm}\right)$ and $\mathrm{C}_{8} / \mathrm{HE}_{6}-\mathrm{AT}(6.4 \pm 0.4 \mathrm{~nm})$. d) Fluorescent traces of Nile Red molecules encapsulated inside $\mathrm{C}_{8} / \mathrm{DNA}$ and $\mathrm{C}_{8} / \mathrm{HE}_{6}$-DNA. The signal of Nile Red was higher in the presence of $\mathrm{HE}_{6}-\mathrm{AT}$. No fluorescent signal was observed in the buffer (see Supporting Information section XIV for details). These observations suggest the formation of hydrophobic core inside the cube. 


\section{Cages: structures and sizes of the cages}

The clip-by-clip approach allows the efficient construction of cages with various geometries and sizes. This geometric variation offers more design parameters to control the number and the orientation of the polymers on the cages. It allows us to answer the question: can the cage geometry change the onset of assembly? To investigate this effect, triangular prism (TP) and pentagonal prism (PP) were assembled with $\mathrm{HE}_{\mathrm{n}}$-DNA in an analogous way to the cube $\mathrm{C} / \mathrm{HE}_{\mathrm{n}}$-DNA. With these chains on one face of the cage, the hydrophobically driven aggregation numbers for $\mathrm{TP}_{3}$ and $\mathrm{PP}_{5}$ were indeed different from those of the cube $\mathrm{C}_{4}$. With $\mathrm{HE}_{6}$-DNA on one face, $\mathrm{TP}_{3}$ gave dimer, trimer and tetramer while $\mathrm{C}_{4}$ and $\mathrm{PP}_{5}$ gave only dimer and trimer (see Supplementary Figure 6 and 7 for $\mathrm{TP}_{3}$ and $\mathrm{PP}_{5}$ ). This can be explained by the smaller size of the triangular prism, allowing more cages to fit around the hydrophobic core. Thus, aggregation number can be tuned with the cage geometry.

With $\mathrm{HE}_{\mathrm{n}}$-DNA on both faces, we expect that the smaller triangular prism can accommodate shorter polymer chains in its core than the cube, and the pentagonal prism would encapsulate larger polymer chains. Indeed, $\mathrm{TP}_{6}$ could accommodate lengths up to $\mathrm{HE}_{5}$ within its core (capacity $30 \mathrm{HE}$ units), before the cage started to dimerize with $\mathrm{HE}_{6}$; this transition occurred from $\mathrm{HE}_{6}$ to $\mathrm{HE}_{7}$ for the cube (capacity $48 \mathrm{HE}$ units), and from $\mathrm{HE}_{7}$ to $\mathrm{HE}_{8}$ for the pentagonal prism (capacity $70 \mathrm{HE}$ units, Figure 6a). The larger cages and higher total number of HE repeats per cage can in principle increase the loading capacity of hydrophobic guests. To verify this, we compared the loading capacity of the three different cages decorated with $\mathrm{HE}_{6}$-DNA (Figure $6 \mathrm{~b}$ ). The results showed an approximately 2.5 -fold increase in Nile Red loading capacity when the size of cages and thus total number of $\mathrm{HE}_{6}$-DNA increased: 9.1 \pm 1.7 molecules per $\mathrm{PP}_{10} / \mathrm{HE}_{6}$-DNA, 3.6 \pm 1.2 molecules per $\mathrm{C}_{8} / \mathrm{HE}_{6}$-DNA and $1.5 \pm 0.4$ molecules per $\mathrm{TP}_{6} / \mathrm{HE}_{6}{ }^{-}$ DNA.

We had previously shown that the $\mathrm{HE}_{6}$-DNA conjugate forms micelles with a diameter of $\sim 13$ nm. ${ }^{15}$ Yet if this polymer is fully stretched, it has a $\sim 7 \mathrm{~nm}$ long DNA portion and a $\sim 12 \mathrm{~nm}$ long hydrophobic chain. Considering the efficient chain packing of polyethylene ${ }^{29}$ and the fact that HE chains are punctuated by phosphate groups, it is possible that they fold upon themselves to enable tight packing between adjacent HE repeats ${ }^{15}$ in a similar way to the arrangement of phospholipid bilayers and bolaamphiphiles. $^{30,31}$ This would result in a smaller micelle size and a tighter, more densely packed hydrophobic core. The same tight chain packing may be present in the core of the 'micellar cages' above, which may explain their relatively low loading capacity. It has been shown that the crystallinity of the hydrophobic core of block copolymer micelles tends to decrease the loading capacity for guest molecules, because of lower chain mobility that hinders the diffusion of the hydrophobic molecules. ${ }^{32-34}$ While 
additional studies need to be performed to better understand the chain packing in our 'micellar cages', we will also examine reducing the extent of core packing by using unsaturated lipids, rather than HE chains as the hydrophobic units.
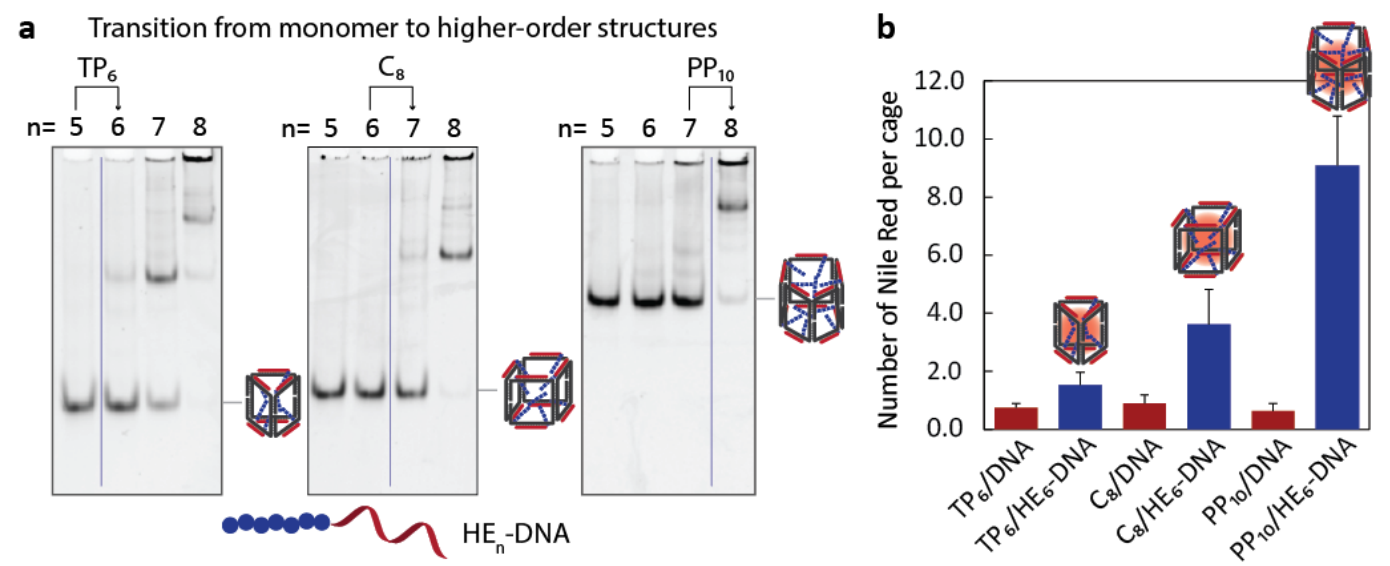

Figure 6. Effect of the cage's structure. a) Native PAGE showing the assembly products of triangular prism $\mathrm{TP}_{6}$, cube $\mathrm{C}_{8}$ and pentagonal prism $\mathrm{PP}_{10}$ with $\mathrm{HE}_{5}$-DNA to $\mathrm{HE}_{9}$-DNA. Larger cages could provide more space for the hydrophobic core and therefore can accommodate longer $\mathrm{HE}_{\mathrm{n}}$-DNA without forming higher-order structures. ( $\mathrm{HE}_{5}$-DNA for $\mathrm{TP}_{6}, \mathrm{HE}_{6}$-DNA for $\mathrm{C}_{8}$ and $\mathrm{HE}_{7}-\mathrm{DNA}$ for $\mathrm{PP}_{10}$ ). b) Nile Red encapsulation in double-stranded cages (red bars) and cages decorated with $\mathrm{HE}_{6}$-DNA (blue bars). There was a $\sim 2.5$-fold increase in loading capacity with increased cage size.

\section{Assembly dynamics and thermodynamic properties}

The cage architectures described here were all generated by a one-step thermal annealing protocol (95 to $4^{\circ} \mathrm{C}$ ) where all component strands and DNA polymers are mixed and annealed together. There are two possible mechanisms for their assembly: (i) as the strands are cooled from $95^{\circ} \mathrm{C}$, the cage assembles first, followed by hybridization to the individual DNA-polymer strands; then subsequent hydrophobic interactions drive the assembly of super-structures as the temperature further decreases. (ii) the DNA cage and the micelles pre-form separately, and the two objects hybridize together into the final structure, thus transitioning from a micelle morphology to cube superstructures. To explore this mechanistic aspect, we pre-assembled cube $\mathrm{C}_{4}$ and $\mathrm{HE}_{\mathrm{n}}$-DNA separately, and then incubated them together at room temperature for 30 minutes (see Supplementary Figure 58). Short $\mathrm{HE}$ chains ( $\mathrm{HE}_{1}$-DNA to $\mathrm{HE}_{4}-\mathrm{DNA}$ ) that are not expected to form stable micelles yielded monomeric structures similar to the one-pot assembly. On the other hand, the two-step assembly process with longer chains ( $\mathrm{HE}_{6}$-DNA to $\mathrm{HE}_{12}$-DNA) resulted in non- 
penetrating bands, as well as unfunctionalized DNA cube. (Figure 7a and see Supplementary Figure 58 in Supporting Information). Thus, in this case, the cube cannot disassemble pre-formed micelles in order to hybridize with their individual chains at room temperature. Interestingly for $\mathrm{HE}_{7}$-DNA and $\mathrm{HE}_{8}$-DNA, increasing the incubation temperature to $37^{\circ} \mathrm{C}$ converted the mixture of higher-order structures and cube into the cube dimers and trimers observed earlier (Figure 7a and see Supplementary Figure 59 and Supplementary Figure 60 for temperature dependence). At this temperature, the HE chains in the micelle may possibly rearrange into the more thermodynamically favorable cube-aggregate state. Thus a preformed DNA-polymer spherical micelle can shape-shift into quantized cage assemblies, merely by adding DNA cages at $37^{\circ} \mathrm{C}$.

The second question that we would like to address is the possibility of shape discrimination, i.e., whether two DNA cages of the same geometry would prefer to associate together via hydrophobic interactions. In a one-pot annealing of $\mathrm{HE}_{6}$-DNA with both the triangular prism $\mathrm{TP}_{3}$ and cube $\mathrm{C}_{4}$ strands, we found no selectivity in the cage structures: for example, homo- and heterodimer combinations of $\mathrm{TP}_{3}$ $\mathrm{TP}_{3}, \mathrm{TP}_{3}-\mathrm{C}_{4}$ and $\mathrm{C}_{4}-\mathrm{C}_{4}$ were observed (Figure $7 \mathrm{~b}$, left gel). However, if $\mathrm{TP}_{3}-\mathrm{TP}_{3}$ and $\mathrm{C}_{4}-\mathrm{C}_{4}$ homodimers were separately generated and mixed together at room temperature for 30 minutes, no observable exchange occured. (Figure $7 \mathrm{~b}$, right gel). At $37^{\circ} \mathrm{C}$, scrambling started to happen (Figure $7 \mathrm{~b}$, middle gel). Additionally, we verified the formation of this heterodimer by labeling each of the cube $\mathrm{C}_{4}$ and triangular prism $\mathrm{TP}_{3}$ with two dyes of different emission colors, and observing co-localization by gel electrophoresis imaging (Supplementary Figure 64). Because of its stability at room temperature, it is possible to isolate the heterodimer (for example, $\mathrm{TP}_{3}-\mathrm{C}_{4}$ ) to generate anisotropic nanoparticles, whose free single-stranded faces can be of different sequences and can provide unique sites for further functionalization.

a
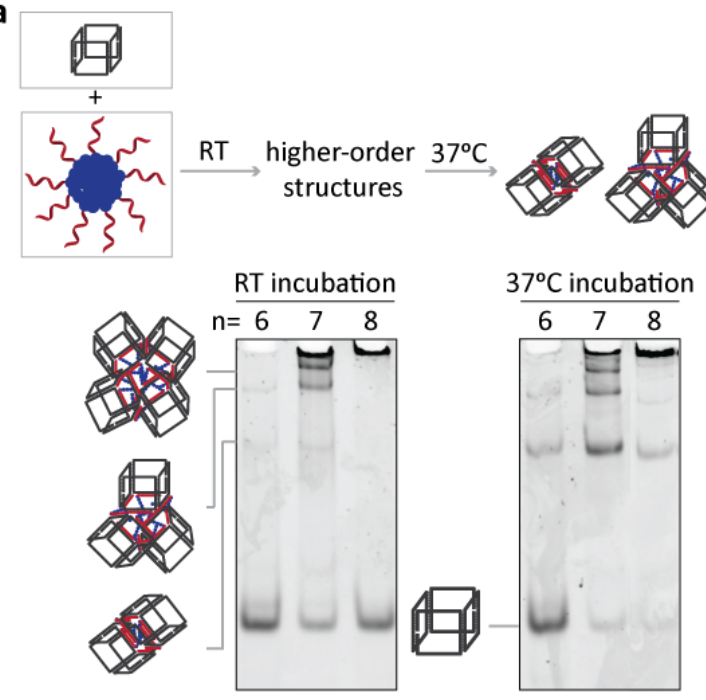

b
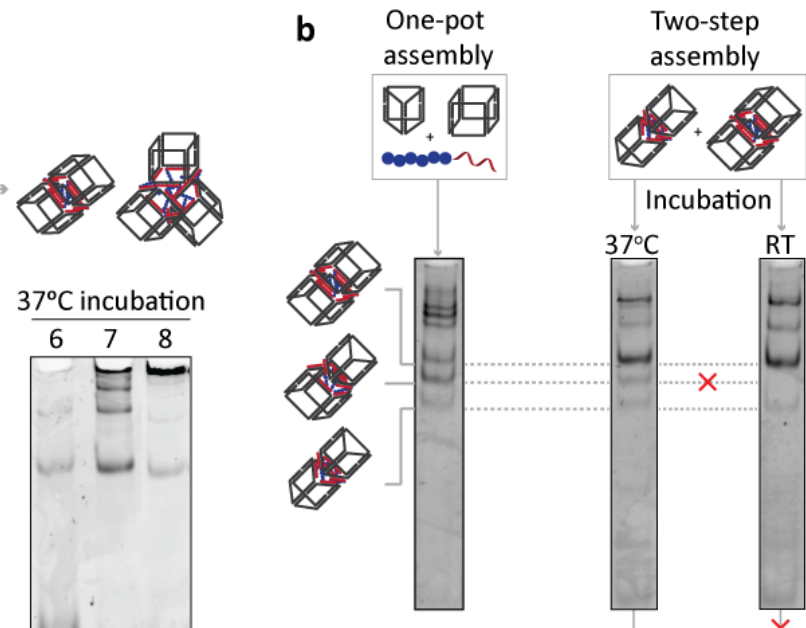

Incubation

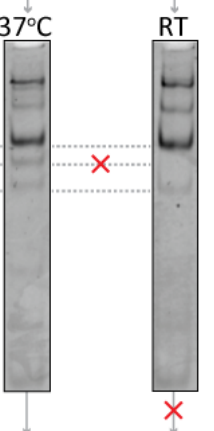

Cage exchange

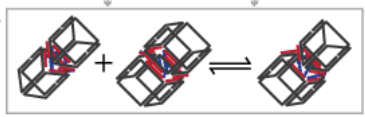


Figure 7. Assembly dynamics of the quantized structures. a) Mixing of separately pre-assembled cubes and $\mathrm{HE}_{\mathrm{n}}$-DNA $(\mathrm{n}=6,8)$ micelles generated larger aggregates. Increasing incubation temperature converted these structures back to small structures (dimers, trimers and tetramers) observed in the one-pot assembly. b) As representative examples, only the bands corresponding to dimers were labeled. One-pot annealing of $\mathrm{TP}_{3}, \mathrm{C}_{4}$ and $\mathrm{HE}_{6}$-DNA generated all cage combinations such as dimers of $\mathrm{TP}_{3} / \mathrm{TP}_{3}, \mathrm{TP}_{3} / \mathrm{C}_{4}$ and $\mathrm{C}_{4} / \mathrm{C}_{4}$ (left gel). Mixing separately preformed $\mathrm{TP}_{3} / \mathrm{HE}_{6}$-DNA and $\mathrm{C}_{4} / \mathrm{HE}_{6}$-DNA at room temperature did not result in exchange (right gel). Incubation at $37^{\circ} \mathrm{C}$ for 30 minutes resulted in scrambling to the heterodimer $\left(\mathrm{TP}_{3} / \mathrm{C}_{4}\right)$.

Decoration of $\mathrm{HE}_{6}$-DNA on the cube $\mathrm{C}_{8}$ with 8 binding sites resulted in a totally different mode of $\mathrm{HE}$ chain interactions, as compared to cube $\mathrm{C}_{4}$. Here, the pre-organization of $8 \mathrm{HE}_{6}$ chains on $\mathrm{C}_{8}$ increased the extent of intra-scaffold 'handshake' of these chains over inter-scaffold 'handshake'. This is likely due to the lower entropic penalty of the intramolecular assembly, and the increase in the effective concentration of $\mathrm{HE}_{6}$ in the DNA cage core, thus favoring micellization below the critical micelle concentration of the polymers. ${ }^{15}$ Thermal denaturation analysis was performed to investigate the thermodynamic properties of these 'micellar cage'. Interestingly, the presence of $\mathrm{HE}_{6}$ chains in the core of the cube provided significant stabilization of $\mathrm{C}_{8} / \mathrm{DNA}$, with an increase of $5.5^{\circ} \mathrm{C}$ in thermal denaturation (Figure 8a). The full width at half-maximum (FWHM) determined from the first derivatives of the melting curves can be used as the indication for the degree of cooperativity. ${ }^{35,36}$ The dramatic decrease in FWHM of $\mathrm{C}_{8} / \mathrm{HE}_{6}$-DNA $\left(4.0 \pm 0.1^{\circ} \mathrm{C}\right)$ in comparison to $\mathrm{C}_{4} / \mathrm{DNA}\left(10.1 \pm 1.0^{\circ} \mathrm{C}\right)$ indicated a significantly increased positive cooperativity of DNA nanostructure assembly/disassembly. To confirm this cooperativity, we performed a titration experiment, in which increasing quantities of $\mathrm{HE}_{6}$-DNA were added to $\mathrm{C}_{8}$ (Supplementary Figure 56). All-or-none binding was observed with sub-stoichiometric amounts of the DNA polymer with respect to the cube binding sites. On the other hand, titration of $\mathrm{C}_{8}$ with unmodified DNA strands gave intermediate structures and did not exhibit such a cooperativity (Supplementary Figure 56). Thus with the intra-scaffold handshake, the DNA base-pairing and hydrophobic effects are acting synergistically, providing greater stability and assembly cooperativity to the cube-micelle structures. This is of significant importance for the biological applications of these structures.

We hypothesized that decoration of $\mathrm{HE}_{6}$-DNA on only one face of the cage $\left(\mathrm{C}_{4}\right)$ would not affect DNA hybridization to the same extent. $\mathrm{C}_{4} / \mathrm{HE}_{6}$-DNA exhibited a slight increase of $2^{\circ} \mathrm{C}$ in $\mathrm{T}_{\mathrm{m}}$ compared to $\mathrm{C}_{4} /$ DNA (Figure $8 \mathrm{~b}$ ). Interestingly, increased cooperativity was also observed in this system, as indicated 
by a significant decrease in FWHM $\left(10.3 \pm 1.8^{\circ} \mathrm{C}\right.$ for $\mathrm{C}_{4} / \mathrm{DNA}$ and $4.5 \pm 0.7^{\circ} \mathrm{C}$ for $\left.\mathrm{C}_{4} / \mathrm{HE}_{6}-\mathrm{DNA}\right)$. A comparable increase in $\mathrm{T}_{\mathrm{m}}$ and decrease in FWHM was observed for $\mathrm{C}_{4} / \mathrm{HE}_{12}$-DNA. Moreover, some extra stabilization was also observed in assemblies with block copolymers $H_{E G_{n}}-H_{n}-D N A$. Hence, the hydrophobic HE chains contribute to greater stabilization and cooperativity for DNA assemblies; this additional stabilization possibly stems from some additional intra-scaffold interactions between HE chains, providing extra cohesion to the assembly. Therefore, the hydrophobic interactions can not only introduce new DNA assembly modes but also synergistically work together with the base-pairing interactions to form and stabilize the DNA nanostructures.
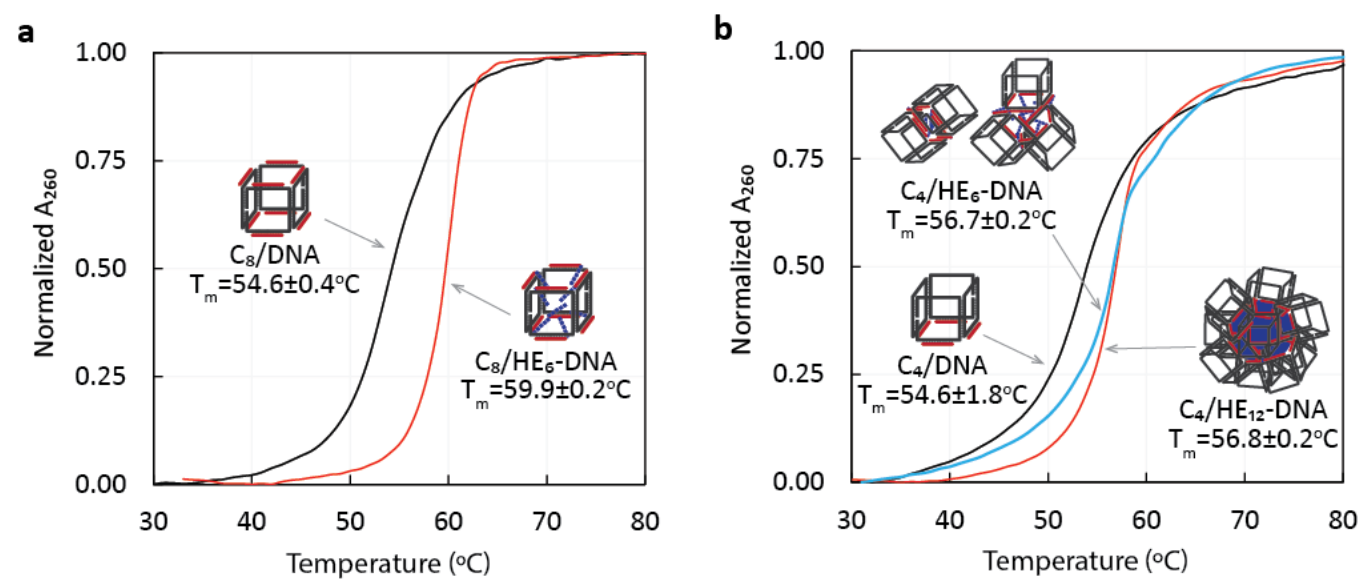

Figure 8. Melting profiles of the assemblies of a) $\mathrm{C}_{8} / \mathrm{DNA}$ and $\mathrm{C}_{8} / \mathrm{HE}_{6}$-DNA; b) $\mathrm{C}_{4} / \mathrm{DNA}_{2} \mathrm{C}_{4} / \mathrm{HE}_{6}-\mathrm{DNA}$ and $\mathrm{C}_{4} / \mathrm{HE}_{12}$-DNA. An increase in melting temperature $\left(\mathrm{T}_{\mathrm{m}}\right)$ of the cubes with $\mathrm{HE}_{\mathrm{n}}$-DNA suggested the synergistic stabilization of DNA nanostructures by the hydrophobic interactions. The narrow transition of the curve is consistent with a large increase in cooperativity of DNA hybridization/dissociation in the presence of hydrophobic chains.

\section{Conclusion}

We have demonstrated the use of sequence-defined hydrophobic polymers to provide orthogonal assembly modes to DNA cages and to synergistically work together with base pairing interactions. A range of new structures can be accessed by fine-tuning of the length of hydrophobic blocks, the sequence order of the polymers and the orientation of the polymers on the cages. Short hydrophobic chains result in monomeric DNA cage structures that are decorated with alkyl or oligoethylene glycol units. Longer hydrophobic chains arranged on one face of the DNA prismatic cage result in quantized cube higher-order structures; here, the number of hydrophobic repeats defines the number of DNA cages that form these 
aggregates. When these hydrophobic chains are organized on both faces of the cage, these chains point to the interior of the cage and undergo an intra-scaffold 'handshake'. The sequence order of hydrophobic and hydrophilic monomers on the polymer chains can significantly control the interactions between hydrophobic blocks, resulting in monomeric cages and 'doughnut-shaped' DNA cage-ring structures for specific sequences. These DNA-polymer nanostructures can be alternatively viewed as amphiphilic block copolymers, where the hydrophilic block consists of a DNA cage, and the hydrophobic block has hexaethylene chains. However, unlike block copolymers, the two components are monodisperse, sequence defined, and the placement of hydrophobic polymers on the DNA cage is anisotropic. This gives rise to entirely new morphologies that are not observed with block copolymers, and provides guidelines for the design of DNA nanostructures mediated by hydrophobic interactions. It is remarkable that high specificity is achieved in these assembled structures despite the fact that the hydrophobic effect is one of the least directional supramolecular interactions. We have only worked with hydrophobic interactions so far, but the potential for structural complexity and protein-inspired folding is tremendous when additional interactions (fluorophilic, metal-binding, etc.) are introduced.

Supporting Information. DNA cage design and assembly, determination of cage aggregation number, gold nanoparticle labeling, characterization by DLS, AFM and TEM, Nile red encapsulation, studies of stability and cooperativity, effect of cage geometry and concentration, isolation of cage aggregates.

\section{AUTHOR INFORMATION}

\section{Corresponding Author}

*hanadi.sleiman@mcgill.ca

\section{Acknowledgements}

The authors thank NSERC, CFI, CSACS, CIHR and FQRNT for funding. H.F.S. is a Cottrell Scholar of the Research Corporation. We thank Dr. Alexander Wahba for his help with MS characterization.

\section{References}

(1) Lutz, J.-F.; Ouchi, M.; Liu, D. R.; Sawamoto, M. Science 2013, 341.

(2) Aldaye, F. A.; Palmer, A. L.; Sleiman, H. F. Science 2008, 321, 1795.

(3) Winfree, E.; Liu, F.; Wenzler, L. A.; Seeman, N. C. Nature 1998, 394, 539.

(4) Yan, H.; Park, S. H.; Finkelstein, G.; Reif, J. H.; LaBean, T. H. Science 2003, 301, 1882.

(5) Liu, D.; Wang, M.; Deng, Z.; Walulu, R.; Mao, C. J. Am. Chem. Soc. 2004, 126, 2324.

(6) He, Y.; Chen, Y.; Liu, H.; Ribbe, A. E.; Mao, C. J. Am. Chem. Soc. 2005, 127, 12202. 
(7) Chen, J. H.; Seeman, N. C. Nature 1991, 350, 631.

(8) Rothemund, P. W. Nature 2006, 440, 297.

(9) Aldaye, F. A.; Sleiman, H. F. J. Am. Chem. Soc. 2007, 129, 13376.

(10) McLaughlin, C. K.; Hamblin, G. D.; Aldaye, F. A.; Yang, H.; Sleiman, H. F. Chem. Commun. 2011, 47, 8925.

(11) Wei, B.; Dai, M.; Yin, P. Nature 2012, 485, 623.

(12) Mai, Y.; Eisenberg, A. Chem. Soc. Rev. 2012, 41, 5969.

(13) Woo, S.; Rothemund, P. W. K. Nat Chem 2011, 3, 620.

(14) Edwardson, T. G.; Carneiro, K. M.; McLaughlin, C. K.; Serpell, C. J.; Sleiman, H. F. Nat Chem 2013, 5, 868.

(15) Edwardson, T. G.; Carneiro, K. M.; Serpell, C. J.; Sleiman, H. F. Angew. Chem. Int. Ed. 2014, 53, 4567.

(16) Chen, Y.-J.; Groves, B.; Muscat, R. A.; Seelig, G. Nat Nano 2015, 10, 748.

(17) Bujold, K. E.; Fakhoury, J.; Edwardson, T. G. W.; Carneiro, K. M. M.; Briard, J. N.; Godin, A. G.; Amrein, L.; Hamblin, G. D.; Panasci, L. C.; Wiseman, P. W.; Sleiman, H. F. Chem. Sci. 2014, 5, 2449.

(18) Hamblin, G. D.; Carneiro, K. M.; Fakhoury, J. F.; Bujold, K. E.; Sleiman, H. F. J Am Chem Soc 2012, 134, 2888.

(19) Fakhoury, J. J.; McLaughlin, C. K.; Edwardson, T. W.; Conway, J. W.; Sleiman, H. F. Biomacromolecules 2014, 15, 276.

(20) Lee, H.; Lytton-Jean, A. K. R.; Chen, Y.; Love, K. T.; Park, A. I.; Karagiannis, E. D.; Sehgal, A.; Querbes, W.; Zurenko, C. S.; Jayaraman, M.; Peng, C. G.; Charisse, K.; Borodovsky, A.; Manoharan, M.; Donahoe, J. S.; Truelove, J.; Nahrendorf, M.; Langer, R.; Anderson, D. G. Nat Nano 2012, 7, 389.

(21) List, J.; Weber, M.; Simmel, F. C. Angew. Chem. Int. Ed. 2014, 53, 4236.

(22) Zhou, C.; Wang, D.; Dong, Y.; Xin, L.; Sun, Y.; Yang, Z.; Liu, D. Small 2015, 11, 1161.

(23) Wilks, T. R.; Bath, J.; de Vries, J. W.; Raymond, J. E.; Herrmann, A.; Turberfield, A. J.; O'Reilly, R. K. ACS Nano 2013, 7, 8561.

(24) Serpell, C. J.; Edwardson, T. G.; Chidchob, P.; Carneiro, K. M.; Sleiman, H. F. J. Am. Chem. Soc. 2014, 136, 15767.

(25) Ko, S.; Liu, H.; Chen, Y.; Mao, C. Biomacromolecules 2008, 9, 3039.

(26) Walsh, A. S.; Yin, H.; Erben, C. M.; Wood, M. J. A.; Turberfield, A. J. ACS Nano 2011, 5,

5427.

(27) Buckhout-White, S.; Ancona, M.; Oh, E.; Deschamps, J. R.; Stewart, M. H.; BlancoCanosa, J. B.; Dawson, P. E.; Goldman, E. R.; Medintz, I. L. ACS Nano 2012, 6, 1026.

(28) Greenspan, P.; Mayer, E. P.; Fowler, S. D. J. Cell Biol. 1985, 100, 965.

(29) Ehrenstein, G. W.; Theriault, R. P. Polymeric materials : structure, properties, applications; Hanser ; Hanser Gardner Publications: Munich; Cincinnati, OH, 2001.

(30) Fuhrhop, J.-H.; Wang, T. Chem. Rev. 2004, 104, 2901.

(31) Blume, A.; Drescher, S.; Meister, A.; Graf, G.; Dobner, B. Faraday Discuss. 2013, 161, 193.

(32) Shuai, X.; Ai, H.; Nasongkla, N.; Kim, S.; Gao, J. J. Controlled Release 2004, 98, 415.

(33) Glavas, L.; Odelius, K.; Albertsson, A.-C. Polym. Adv. Technol. 2015, $26,880$.

(34) Gou, J.; Feng, S.; Xu, H.; Fang, G.; Chao, Y.; Zhang, Y.; Xu, H.; Tang, X. Biomacromolecules 2015, 16, 2920.

(35) Eryazici, I.; Prytkova, T. R.; Schatz, G. C.; Nguyen, S. T. J. Am. Chem. Soc. 2010, 132, 17068.

(36) Greschner, A. A.; Toader, V.; Sleiman, H. F. J. Am. Chem. Soc. 2012, 134, 14382. 


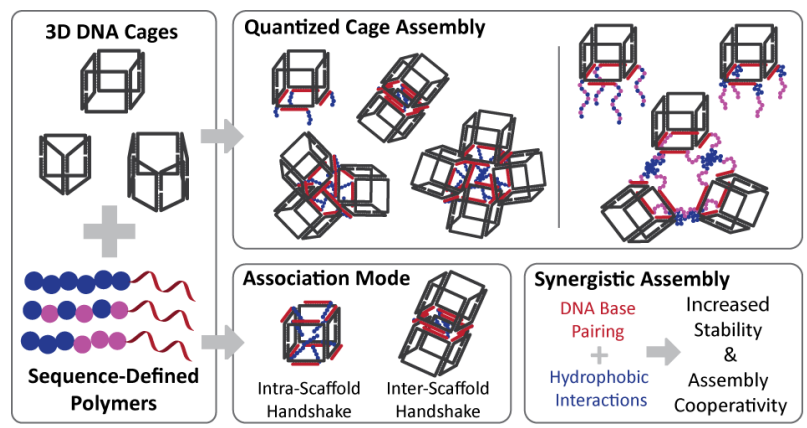

